\title{
Contribución al estudio de la epidemiología de la enfermedad de Chagas en tres localidades de la zona sur del Perú
}

\author{
HILDA SOLÍS ${ }^{1,2}$, ESTHER DE CARVALHO ${ }^{3}$, CLAUDIO FERREIRA $^{4}$, CLAUDIO CASANOVA $^{3}$, \\ ANA HUAMÁN ${ }^{1,2}$, VICTORIA MENDOZA ${ }^{1,2}$ \\ ${ }^{1}$ Instituto de Medicina Tropical "Daniel A. Carrión”-UNSMM. ${ }^{2}$ Departamento Académico de Microbiología Médica, \\ Facultad de Medicina-UNMSM. ${ }^{3}$ Pesquisadores de la Super Intendencia de control de Endemias (SUCEN) \\ Sao Paulo - Brasil. ${ }^{4}$ Universidad de Sao Paulo, Facultad de Ciencias Biomédicas Sao Paulo - Brasil
}

\begin{abstract}
RESUMEN
OBJETIVOS: Investigar en humanos la presencia de anticuerpos IgG anti-Trypanosoma cruzi y los hábitos alimenticios de triatominos de las viviendas de 3 localidades de la provincia de Nasca, Perú. MATERIAL Y MÉTODOS: Estudio de anticuerpos IgG anti-T. cruzi por medio de los métodos RIFI y ELISA en muestras de sangre de 867 habitantes (excluidos los menores de un año), en las localidades de Tulín, Vista Alegre y Changuillo, para evaluar el problema de la enfermedad de Chagas. Además se investigó las condiciones de 494 casas, se capturó 581 ejemplares de Triatoma infestans (411 ninfas y 170 adultos) y se examinó su contenido intestinal, para la identificación de sus hábitos alimenticios y búsqueda de $T$. cruzi. RESULTADOS: Se identificó anticuerpos IgG anti-T. cruzi en muestras de 128 personas $(14,8 \%), 89(15,9 \%)$ de sexo femenino y $39(12,6 \%)$ de sexo masculino. La reacción de precipitina en tubo capilar (8 antígenos) identificó en 401 insectos $(69,0 \%)$ sus fuentes de alimento, siendo las principales: aves 252 (43,4\%), roedores $36(6,2 \%)$, humano $23(3,9 \%)$ y perro $(1,6 \%)$. Una hembra de $T$. infestans se encontró infectada por $T$. cruzi. CONCLUSIONES: La prevalencia en humanos fue de $14,8 \%$. En relación a los hábitos alimenticios, la ingesta de sangre humana se encontró en3,9\% de los triatominos, lo cual indica factor de riesgo para contraer la enfermedad de Chagas.
\end{abstract}

Palabras clave: Enfermedad de Chagas; Trypanosoma cruzi; triatominae; triatoma.

\section{CONTRIBUTION TO THE STUDY OF CHAGAS DISEASE EPIDEMIOLOGY IN THREE SOUTHERN PERU LOCALITIES SUMMARY}

OBJECTIVES: To determine the presence of IgG anti-Trypanosoma cruzi antibodies in humans and the triatomines feeding habits in 3 Nasca, Peru provinces housings. MATERIAL AND METHODS: IgG anti-T. cruzi antibodies were studied by RIFI and ELISA methods in 867 inhabitants blood samples (excluding less than one year-old children) in Tulin, Vista Alegre and Changuillo localities in order to determine Chagas disease. We also investigated 494 houses conditions, captured 581 samples of Triatoma infestans (411 nymphs and 170 adults) and intestinal contents were studied for feeding habits and search for T. cruzi. RESULTS: We identified IgG anti-T. cruzi antibodies in 128 inhabitants samples $(14,8 \%), 89(15,9 \%)$ females and $39(12,6 \%)$ males. Precipitine reaction in capillary tube (8 antigens) identified feeding origin in 401 insects $(69,0 \%)$, mainly birds $252(43,4 \%)$, rodents 36 $(6,2 \%)$, humans $23(3,9 \%)$ and dogs $(1,6 \%)$. One $T$. infestans female was found infected with $T$. cruzi. CONCLUSIONS: Human positivity of Trypanosoma cruzi antibodies was 14,8\% and human blood ingestion was found in 3,9\% of triatomines, representing a risk factor for Chagas disease.

Key words: Chagas disease; Trypanosoma cruzi; triatominae; triatoma.

Correspondencia:

Dra. Hilda Solis Acosta

Instituto de Medicina Tropical "Daniel A. Carrión"

UNMSM - Sección de Parasitología.

Jr. José Santos Chocano 199. Urb. San Joaquín

Callao 02, Perú

E-mail: hildamarias3@hotmail.com 


\section{INTRODUCCIÓN}

La enfermedad de Chagas o Tripanosomiasis americana producida por Trypanosoma cruzi es un problema de salud pública que se agrava debido a la dispersión del vector, la migración de personas infectadas hacia regiones libres de infección y las condiciones socioeconómicas precarias $\left({ }^{1,2}\right)$. La antigüedad de la enfermedad en el Perú fue demostrada por el hallazgo en territorio peruano de momias pertenecientes a culturas prehispánicas de los siglos XIV y XV presentando formas crónicas de la enfermedad ${ }^{(3)}$. Aún es poco conocida la situación de la provincia de Nasca, en cuanto a la prevalencia de la enfermedad de Chagas. Los datos existentes son aislados, no existiendo aún un estudio más completo en esta región $\left({ }^{4}\right)$. El presente trabajo se dirige a estimar, de modo más amplio, algunos factores relacionados con la prevalencia de la infección chagásica en personas de ambos sexos, residentes en las localidades de Tulín, Vista Alegre y Changuillo. Su distribución etárea deberá indicar una relación entre tiempo de residencia y adquisición de la infección $\left(^{5}\right)$. Otro dato importante, aún no disponible en el Perú, es la determinación de las fuentes de alimento de triatominos ("chirimachas"), siendo la única especie descrita para esa región Triatoma infestans.

A través de este trabajo procuramos evaluar la magnitud del problema de la enfermedad de Chagas en las localidades en cuestión; la cual fue investigada, por medio de reacciones de inmunofluorescencia indirecta (RIFI) y ensayo inmunoenzimático (ELISA), la presencia de anticuerpos IgG anti- Trypanosoma cruzi en habitantes representativos de la población general de esas localidades, con un año o más de edad y de ambos sexos. Se procedió a la investigación de señales de colonización de las casas y anexos por triatominos y su eventual captura.

De los ejemplares capturados (todos identificados como T. infestans) fueron retiradas muestras de contenido intestinal para la búsqueda (en preparaciones en fresco) de formas evolutivas de $T$. cruzi y aplicar la reacción de precipitina en tubo capilar para la identificación de los hábitos alimenticios de los triatominos capturados.

\section{MATERIAL Y MÉTODOS}

La provincia de Nasca, donde se encuentran las localidades de Tulín, Vista Alegre y Changuillo, pertenece al Departamento de Ica, región Sur del Perú, zona desértica, con raras precipitaciones pluviales y temperatura que varía entre $19^{\circ} \mathrm{C}$ y $35^{\circ} \mathrm{C}$ anualmente $\left({ }^{6}\right)$. El presente estudio transversal fue realizado en los años 1997 y 1998. Incluyó la investigación de 867 personas de un año o más de edad, de ambos sexos, distribuidas en 494 unidades domiciliarias (UDs), en su mayoría colonizadas por Triatoma infestans. Entre los habitantes de esas localidades persiste la costumbre, que proviene de épocas precolombinas, de mantener cobayos (Cavia cobaya) - "cuy" en el lenguaje de los lugareñosademás de aves, en el interior de sus casas, frecuentemente acompañadas por conejos, gatos, perros y otros mamíferos.

Los datos referentes a los habitantes lugareños, recolectados en formularios previamente elaborados, fueron transferidos a una base de datos. Las muestras de sangre recolectadas por punción del pulpejo del dedo fueron absorbidos en papel filtro Whatman \# $3\left(^{7}\right)$ y se aplicó RIFI y ELISA para la detección de anticuerpos IgG anti T. cruzi, utilizando eluidos de este material. La investigación de hábitos alimenticios fue hecha en muestras de contenido intestinal absorbidas en papel filtro, obtenidas de 581 ejemplares de triatominos. Se adaptó la técnica de precipitina en tubo capilar $\left({ }^{8}\right)$ con 8 antígenos: H (humano), A (ave), R (roedor), $\mathrm{C}$ (perro), Gto (gato), P (puerco), Cb (cabra), preparados en conejo (primer trabajo de estudios de hábitos alimenticios en el Perú).

\section{RESULTADOS}

De las 867 muestras de sangre de personas de la población general, de ambos sexos de un 
Tabla 1.- Distribución por localidad, sexo y positividad.

\begin{tabular}{|c|c|c|c|c|c|c|c|c|c|c|c|c|}
\hline \multirow{3}{*}{$\begin{array}{r}\text { Localidad } \\
\text { S }\end{array}$} & \multirow{3}{*}{ Sub localidad } & \multicolumn{3}{|c|}{ Masculino } & \multicolumn{3}{|c|}{ Femenino } & \multicolumn{3}{|c|}{ Masculino+Femenino } & \multicolumn{2}{|c|}{ IC $(95 \%)$} \\
\hline & & \multirow[t]{2}{*}{ Total } & \multicolumn{2}{|c|}{ Positivo } & \multirow[t]{2}{*}{ Total } & \multicolumn{2}{|c|}{ Positivo } & \multirow[t]{2}{*}{ Total } & \multicolumn{2}{|c|}{ Positivo } & \multirow[t]{2}{*}{ LI } & \multirow[t]{2}{*}{ LS } \\
\hline & & & $\mathrm{n}$ & $\%$ & & $\mathrm{n}$ & $\%$ & & $\mathrm{n}$ & $\%$ & & \\
\hline Tulín & - & 59 & 10 & 16,9 & 88 & 18 & 20,5 & 147 & 28 & 19,1 & 13,52 & 26,2 \\
\hline \multirow[t]{4}{*}{ V. Alegre } & V. Alegre & 70 & 9 & 12,9 & 166 & 14 & 4,4 & 236 & 23 & 9,8 & 6,58 & 14,2 \\
\hline & El Porvenir & 38 & 9 & 23,7 & 92 & 32 & 34,8 & 130 & 41 & 31,5 & 24,18 & 39,9 \\
\hline & N. Unión & 63 & 11 & 17,5 & 123 & 25 & 20,3 & 186 & 36 & 19,4 & 14,32 & 25,6 \\
\hline & Primavera & 13 & 0 & 0,0 & 24 & 0 & 0,0 & 37 & 0 & 0,0 & - & \\
\hline Changuillo & - & 66 & 0 & 0,0 & 65 & 0 & 0,0 & 131 & 0 & 0,0 & - & \\
\hline Total & - & 309 & 39 & 12,6 & 558 & 89 & 15,9 & 867 & 128 & 14,8 & 12,56 & 17,3 \\
\hline
\end{tabular}

$L I=$ Límite inferior, $L I=$ Límite superior, $I C=$ Intervalo de confianza

año o más de edad, 128 (14,8\%) fueron positivas para RIFI y ELISA. De éstas, 89 (15,9\%) eran de sexo femenino y $39(12,6 \%)$ correspondían al sexo masculino (Tabla 1). El tiempo promedio de residencia de las personas pertenecientes a la muestra era de 13,3 años, siendo la mediana de 10 años (Tabla 2). La positividad fue más frecuente en los grupos etáreos inferiores a 35 años.

En las 494 unidades domiciliarias visitadas fueron capturados 581 ejemplares de $T$. infestans, 411 ninfas (de los 5 estadios: 106 N2; 215 N3; $50 \mathrm{~N} 4 ; 40$ N5 y 170 adultos, incluyendo 99 hembras, de las cuales una se encontró infectada por $T$. cruzi y 71 machos). El contenido intestinal del insecto infectado fue inoculado en ratones de la cepa Balb C, para su posterior caracterización. El examen del contenido intestinal de los triatominos, realizado por medio de la reacción de precipitina en tubo capilar, para la determinación de hábitos alimenticios de los 581 triatominos capturados, reveló en 401 muestras (69\%) positividad para por lo menos uno de los antígenos usados: humano $23(3,9 \%)$, ave 252 $(43,4 \%)$, roedor $36(6,2 \%)$, perro $9(1,6 \%)$, gato $1(0,2 \%)$, humano y ave $3(0,5 \%)$, humano y perro $13(2,2 \%)$, humano, ave y gato $1(0,2 \%)$, humano, gato y roedor $1(0,2 \%)$, ave y perro 7 $(1,2 \%)$, ave y puerco $1(0,2 \%)$, ave y roedor 19 $(3,3 \%)$, ave, roedor y cabra $1(0,2 \%)$, roedor y cabra $6(1,0 \%)$, roedor, cabra y puerco $1(0,2 \%)$; $180(30,9 \%)$ no reaccionaron con los antígenos disponibles (Tabla 3).

Tabla 2- Distribución por grupo etáreo, sexo y positividad.

\begin{tabular}{|c|c|c|c|c|c|c|c|c|c|c|c|}
\hline \multirow[t]{3}{*}{ Grupo etáreo } & \multicolumn{3}{|c|}{ Masculino } & \multicolumn{3}{|c|}{ Femenino } & \multicolumn{3}{|c|}{ Masculino+Femenino } & \multicolumn{2}{|c|}{ IC $(95 \%)$} \\
\hline & \multirow[t]{2}{*}{ Total } & \multicolumn{2}{|c|}{ Positivo } & \multirow[t]{2}{*}{ Total } & \multicolumn{2}{|c|}{ Positivo } & \multirow[t]{2}{*}{ Total } & \multicolumn{2}{|c|}{ Positivo } & \multirow[t]{2}{*}{ LI } & \multirow[t]{2}{*}{ LS } \\
\hline & & $\mathrm{n}$ & $\%$ & & $\mathrm{n}$ & $\%$ & & $\mathrm{n}$ & $\%$ & & \\
\hline $0-10$ & 90 & 10 & 11,1 & 69 & 8 & 11,6 & 159 & 18 & 11,3 & 7,3 & 17,2 \\
\hline $10-20$ & 106 & 10 & 9,4 & 212 & 25 & 11,8 & 318 & 35 & 11,0 & 8,0 & 14,9 \\
\hline $20-30$ & 27 & 2 & 7,4 & 93 & 14 & 15,1 & 120 & 16 & 13,3 & 8,4 & 20,6 \\
\hline $30-40$ & 28 & 3 & 10,7 & 83 & 22 & 26,5 & 111 & 25 & 22,5 & 15,8 & 31,1 \\
\hline $40-50$ & 18 & 7 & 38,9 & 45 & 9 & 20,0 & 63 & 16 & 25,4 & 16,3 & 37,3 \\
\hline$>50$ & 40 & 7 & 17,5 & 56 & 11 & 19,6 & 96 & 18 & 18,8 & 12,2 & 27,7 \\
\hline Total & 309 & 39 & 12,6 & 558 & 89 & 15,9 & 867 & 128 & 14,8 & 12,6 & 17,3 \\
\hline
\end{tabular}

$L I=$ Límite inferior, $L I=$ Límite superior, $I C=$ Intervalo de confianza 
Tabla 3.- Hábitos alimenticios de los 581 ejemplares de Triatoma infestans.

\begin{tabular}{|c|c|c|c|c|c|c|c|c|c|c|c|c|c|c|}
\hline Reactivos & $\mathrm{N} 2$ & $\%$ & $\mathrm{~N} 3$ & $\%$ & N4 & $\%$ & N5 & $\%$ & $\mathrm{AH}$ & $\%$ & $\mathrm{AM}$ & $\%$ & Total & $\%$ \\
\hline Humano & 2 & 1,9 & 6 & 2,8 & 5 & 10,0 & 4 & 10,0 & 5 & 5,1 & 1 & 1,4 & 23 & 3,9 \\
\hline Ave & 55 & 51,9 & 107 & 49,8 & 20 & 40,0 & 15 & 37,5 & 29 & 29,3 & 26 & 36,6 & 252 & 43,4 \\
\hline Roedor & 6 & 5,7 & 11 & 5,1 & 5 & 10,0 & 1 & 2,5 & 8 & 8,1 & 5 & 7,0 & 36 & 6,2 \\
\hline Can & 1 & 0,9 & 2 & 0,9 & 0 & 0,0 & 2 & 5,0 & 3 & 3,0 & 1 & 1,4 & 9 & 1,6 \\
\hline Marsupial & 0 & 0,0 & 0 & 0,0 & 0 & 0,0 & 0 & 0,0 & 0 & 0,0 & 0 & 0,0 & 0 & 0,0 \\
\hline Gato & 1 & 0,9 & 0 & 0,0 & 0 & 0,0 & 0 & 0,0 & 0 & 0,0 & 0 & 0,0 & 1 & 0,2 \\
\hline $\mathrm{H} / \mathrm{A}$ & 3 & 2,8 & 14 & 6,5 & 2 & 4,0 & 5 & 12,5 & 4 & 4,0 & 2 & 2,8 & 30 & 5,2 \\
\hline $\mathrm{H} / \mathrm{C}$ & 0 & 0,0 & 2 & 0,9 & 2 & 4,0 & 0 & 0,0 & 6 & 6,1 & 3 & 4,2 & 13 & 2,2 \\
\hline H/A/Gto & 0 & 0,0 & 0 & 0,0 & 0 & 0,0 & 0 & 0,0 & 0 & 0,0 & 1 & 1,4 & 1 & 0,2 \\
\hline $\mathrm{H} / \mathrm{C} / \mathrm{Gto} / \mathrm{R}$ & 0 & 0,0 & 0 & 0,0 & 0 & 0,0 & 0 & 0,0 & 1 & 1,0 & 0 & 0,0 & 1 & 0,2 \\
\hline $\mathrm{A} / \mathrm{C}$ & 0 & 0,0 & 1 & 0,5 & 0 & 0,0 & 0 & 0,0 & 3 & 3,0 & 3 & 4,2 & 7 & 1,2 \\
\hline $\mathrm{A} / \mathrm{Po}$ & 0 & 0,0 & 1 & 0,5 & 0 & 0,0 & 0 & 0,0 & 0 & 0,0 & 0 & 0,0 & 1 & 0,2 \\
\hline $\mathrm{A} / \mathrm{R}$ & 1 & 0,9 & 5 & 2,3 & 2 & 4,0 & 0 & 0,0 & 9 & 9,1 & 2 & 2,8 & 19 & 3,3 \\
\hline $\mathrm{A} / \mathrm{R} / \mathrm{Cb}$ & 0 & 0,0 & 0 & 0,0 & 0 & 0,0 & 0 & 0,0 & 1 & 1,0 & 0 & 0,0 & 1 & 0,2 \\
\hline $\mathrm{R} / \mathrm{C}$ & 0 & 0,0 & 0 & 0,0 & 0 & 0,0 & 2 & 5,0 & 2 & 2,0 & 2 & 2,8 & 6 & 1,0 \\
\hline $\mathrm{R} / \mathrm{C} / \mathrm{Po}$ & 0 & 0,0 & 0 & 0,0 & 0 & 0,0 & 0 & 0,0 & 0 & 0,0 & 1 & 1,4 & 1 & 0,2 \\
\hline SR & 69 & 65,1 & 149 & 69,3 & 36 & 72,0 & 29 & 72,5 & 71 & 71,7 & 47 & 66,2 & 401 & 69,0 \\
\hline NR & 37 & 34,9 & 66 & 31,1 & 14 & 28,0 & 11 & 27,5 & 28 & 28,3 & 24 & 33,8 & 180 & 30,9 \\
\hline Total & 106 & 100,0 & 215 & 100,0 & 50 & 100,0 & 40 & 100,0 & 99 & 100,0 & 71 & 100,0 & 581 & 100,0 \\
\hline
\end{tabular}

$H=$ Humano, $A=$ Ave, $R=$ Roedor, $C=C a n, G=$ Marsupial Gto $=$ Gato, Po=Puerco Cb=Cabra

$N 2=$ ninfa de segundo estadio, N3=ninfa de tercer estadio, $N 4=$ ninfa de cuarto estadio, N5=ninfa de quinto estadio $A M=$ Adulto macho, $A H=$ Adulto hembra, $S R=$ Subtotal reactivos, $N R=$ No reactivos

\section{DISCUSIÓN}

La enfermedad de Chagas existe en el Perú desde épocas remotas, como lo confirman los hallazgos de momias prehispánicas de los siglos XIV y XV DC, presentando estadios crónicos de la enfermedad $\left({ }^{3}\right)$. Escomel $\left({ }^{9}\right)$ publicó el primer trabajo sobre la presencia de la enfermedad de Chagas en el Perú, y Arévalo $\left({ }^{10}\right)$ en la región de Nasca. Villanueva $\left({ }^{11}\right)$ demostró la infección natural de $T$. infestans por T. cruzi en el departamento de Ica.

La prevalencia de la enfermedad chagásica en dos de las tres localidades estudiadas (Tabla 1) está relacionada con la presencia del vector en las UDs. Los grupos etáreos de 1 a 35 años (Tabla 2) de ambos sexos, fueron los más afectados $-87(67,9 \%$ del total de casos reactivos)-, lo que indica transmisión reciente. La mayoría de las personas investigadas -268 (31\%)- provenía de la provincia de Nasca, así como $44(34,4 \%)$ de los positivos. El número de ejemplares de $T$. infestans alimentados con sangre de aves fue siempre mayor, tanto solos como en combinaciones (Tabla 3). Pero, no podemos afirmar que se trate de ornitofilia, ya que las aves son presas fáciles para esos insectos. En segundo lugar está la ingesta de sangre humana sola o en combinaciones, lo que indica factor de riesgo para la población de contraer enfermedad de Chagas. Por lo tanto, son necesarias las medidas de control del vector, teniendo en cuenta que en la región en que se realizó el estudio están presentes todos los eslabones de la cadena epidemiológica, determinando así la presencia, prevalencia y transmisión de la enfermedad.

\section{BIBLIOGRAFÍA}

1. Cornejo J, Cubas R, Solís H, Espinoza I, Alburquerque M, Naupay A, et al. Epidemiología de la enfermedad de 
Chagas en el Departamento de Ica, estudio del vector y reservorio humano. Bol Inst Med Trop 1986; 5:10-3.

2. Pinto JC. Historia Natural da Doença de Chagas. Arq Bras Cardio1995; 65(4): 35966.

3. Fornaciari MG. Chagas disease in a peruvian Inca mummy; in: Congreso Latinoamericano de Parasitología. [Libro de Resúmenes] 1992; 11.

4. Solís AH. Soroepidemiologia do infecção Chagásica em Nasca Perú. [Disertação para obtenção do grau de MESTRE]. São Paulo: Departamento de Análises clínicas e Toxicológicas, Area de Análises Clínicas, Faculdade de Ciências Farmacêuticas, Universidade de São Paulo; 1995.

5. Andrade A. Avaliação de possíveis fatores de risco para infecção pelo Trypanosoma cruzi em crianças estudo caso controle em área rural do Estado de Goias. [Tese apresentada para obtenção do título de DOUTOR em Sãude Pública]. São Paulo: Departamento de Epidemiología, Faculdade de Sãude Pública da Universidade de São Paulo; 1994.
6. Lancho R. Nasca: Datos geográficos- históricos. 2 ed., Lima, Perú: 1987 ED. Calper, p. 72.

7. Ferreira CS, Carvalho DE. Padronização de uso de papel - filtro como suporte de material para reações serológicas. Rev Bras Malariol Doenças Trop 1982; 34: 82-6.

8. De Siqueira FA. Estudo sobre a reação de precipitina aplicada a identificação de sangue ingerido por triatomíneos. Rev Inst Med Trop de São Paulo 1960; 2: 41-53.

9. Escomel E. Insectos hemípteros- heterópteros- hematófagos en nuestros valles del sur del Perú. Reforma Médica 1917; 121-2.

10. Arévalo G. Se ha presentado en Nasca con amenaza de propagarse un peligroso insecto parásito del ser humano y transmite grave enfermedad. La Voz de Ica 1946; 8:073.

11. Villanueva C. Estudio sobre la enfermedad de Chagas en la zona de salud sur Medio - II Nota preliminar acerca de la infección natural de Triatoma infestans por Trypanosoma cruzi en el Distrito de Ica. Rev Peruana Entomol 1973; 16 (1): 124. 